\title{
The significance of psychosocial factors of the working environment in the development of sick building syndrome
}

\author{
Maja Miškulin, Marina Matić ${ }^{1 *}$ Miodrag Beneš ${ }^{3}$ Jelena Vlahović1 \\ ${ }^{1}$ University of Osijek Faculty of Medicine, Osijek, Croatia, ${ }^{2}$ University of Osijek Faculty of Humanities and Social Sciences, \\ Osijek, Croatia, ${ }^{3}$ Health Centre of the Virovitica-Podravska County, Virovitica, Croatia
}

\begin{abstract}
Introduction: Sick building syndrome (SBS) is a medical condition in which people in a certain buildings suffer from symptoms of illness or feeling unwell. The aim of this study was to determine the frequency of exposure of the employees of public institutions from the city of Osijek to harmful psychosocial factors of the working environment, to assess whether there is a connection between the exposure to these factors and the incidence of SBS symptoms and to clarify the nature of this connection.
\end{abstract}

Methods: This cross-sectional study was conducted during May 2013 among 178 employees of public institutions in the city of Osijek. An anonymous questionnaire which contained questions relating to demographic data and working status of the participants, their exposure to various harmful psychosocial factors of the working environment and occurrence of certain symptoms of SBS among them was used as a research tool.

Results: $96.1 \%(171 / 178)$ of participants were exposed to harmful psychosocial factors of the working environment. Employees exposed to those factors more frequently expressed symptoms of SBS. The incidence and the number of symptoms of SBS among employees simultaneously grew with the increase of the number of harmful psychosocial factors of the working environment to which they were exposed.

Conclusion: The study showed positive connection between the exposure to harmful psychosocial factors of the working environment and the incidence of SBS symptoms, highlighting this issue as a very important subject in the field of occupational medicine and health protection in the workplace.

Keywords: Croatia; employee; health; psychosocial factors of the working environment; sick building syndrome

\section{INTRODUCTION}

Sick building syndrome (SBS) was defined for the first time by the World Health Organization in

Corresponding Author: Maja Miškulin, University of Osijek, Faculty of Medicine, Josipa Huttlera 4, 31000 Osijek, Croatia. Fax: +385 160676 86, GSM: +385 9156608 87. E-mail: miskulin.maja@gmail.com

Submitted August 092014 / Accepted: December 202014
1983 (1). The syndrome includes a group of symptoms of unknown etiology which are divided to the symptoms of irritation of the mucous membranes (eyes, nose and throat), skin symptoms such as dry skin and/or eczema or a skin rash as well as the general non-specific symptoms such as headache, nausea, dizziness, feeling of exhaustion and chronic fatigue and also difficulties in concentration. All 
the above mentioned symptoms tend to increase in severity as a function of time spent in the building and improve in a few hours or even disappear when people are away from the building (only the skin takes a few days to recover) (2-5). Although the mechanisms involved in the production of symptoms are largely unknown, in many studies, several factors have been associated with an increased prevalence of SBS symptoms. Studies have shown that SBS can be linked to some personal characteristics of the people who stay in such "sick" buildings such as female sex (6-10) and personal history of allergies $(7,8,11)$. Furthermore, the syndrome has been connected with the existence of several physical risk factors in the working environment such as the presence of moisture in the building $(8,12,13)$, poor ventilation of the building $(6,14)$ as well as an air pollution of the indoor space $(6,15,16)$. Finally it is related to some psychosocial factors of the employees, such as anxiety, position in the work hierarchy and emotional stability $(6,8,17)$, as well as to some psychosocial factors of the working environment such as work overload, stress, lack of cooperation and support among workers as well as various conflict situations in the workplace $(6,8,18)$. Given the previously mentioned risk factors, it is pointed out that lower position in the work hierarchy and higher subordination represents a greater risk factor for the SBS development. Contrary, emotional stability is found to be a protective factor since studies have shown that the emotionally stable people complain less about the symptoms that indicate the SBS $(6,17)$.

Despite the studies which connected the prevalence of SBS with various, previously mentioned potential risk factors, to this very day a definitive cause-and-effect relationship between SBS and neither one of them has not been revealed (11). Experts also disagree about which risk factors could be more important in the development of this syndrome, and while most believe that the syndrome is predominantly related to some physical factors of the working environment, primarily with the poor indoor air quality $(7,11,19-23)$, others point out that in terms of the occurrence of SBS some psychosocial factors of the working environment are more significant (18). In Croatia, the issue of SBS is very poorly studied and to this very day only a few studies of this syndrome were conducted among employees, only from the area of Zagreb and Central Croatia $(17,24,25)$.

The aim of this study was to determine the frequency of exposure of the employees of public institutions from the city of Osijek (Eastern Croatia) to harmful psychosocial factors of the working environment, to assess possible connection among the exposure of employees to these factors and to determine the incidence of one or more SBS symptoms between them.

\section{METHODS}

\section{Study design}

This cross-sectional study was conducted during May 2013 among employees of public institutions in the area of the city of Osijek (Eastern Croatia).

All of the participants voluntarily participated in this study after signing an informed consent, and the entire study was approved by the Ethics Committee of the Osijek Health Centre. Participants were selected randomly among employees of public institutions in the city of Osijek. A total of 300 questionnaires were distributed. The overall response rate was $59.3 \%(178 / 300)$. All of the returned questionnaires were statistically analyzed. Within the final sample of 178 participants, there were $33.7 \%(60 / 178)$ males and $66.3 \%(118 / 178)$ females, with a mean age of $39.3 \pm 10.4$ (range 19-64) years. The sample was stratified according to gender, age or age group (three age groups: 18-32 years, 33-46 years and 47 years and over), length of working experience (3 groups according to length of working experience: 1-9 years, $10-19$ years and 20 or more years of working experience) and level of education of the participants (two groups based on the level of education: a group of participants with secondary or higher education and a group of participants with a university degree).

The questionnaire used in this study was designed to detect the frequency of exposure of study participants to harmful psychosocial factors of the working environment and to evaluate the connection between such exposure and the incidence of one or more symptoms of SBS among examinees. It contained questions relating to gender and age, length of working experience, 
level of education, frequency of occurrence of certain SBS symptoms (such as fatigue, headaches, etc.) and the frequency of exposure to harmful psychosocial factors of the working environment that included: interestingness of work they do, workload in the workplace, ability of the participants to influence the quality of their own work conditions and social support while performing the work by their co-workers.

\section{Statistical analysis}

Upon confirming normality of data distribution by Kolmogorov-Smirnov test, all data were processed by the methods of descriptive statistics. The proportions were calculated and compared by use of $\mathrm{c}^{2}$-test for independent samples or Fisher's exact test. In all statistical analyses, two-sided $\mathrm{P}$ values of 0.05 were considered significant. Statistical analysis was done by the SPSS Statistical Package for Windows, version 13.0 (SPSS Inc., Chicago, IL, USA).

\section{RESULTS}

The study has shown that as many as $96.1 \%$ (171/178) of the participants were exposed to harmful psychosocial factors of the working environment at their workplace. Study further showed that 97.5\% (115/118) female and 93.3\% (56/60) male participants were exposed to harmful psychosocial factors of the working environment.

Among participants exposed to harmful psychosocial factors of the working environment, $43.9 \%$ (75/171) of them have been exposed to one, $45.0 \%$ $(77 / 171)$ of participants have been exposed to two, $8.8 \%(15 / 171)$ of participants have been exposed to three and $2.3 \%(4 / 171)$ of participants have been exposed to four harmful psychosocial factors of the working environment. According to the type of harmful psychosocial factor of the working environment to which participants were exposed, $93.0 \%(159 / 171)$ of them reported excessive workload, 52.6\% (90/171) reported the inability to influence the quality of their own work conditions, $12.9 \%(22 / 171)$ reported the lack of social support from their co-workers while performing the work and $9.9 \%$ (17/171) reported performing uninteresting work and work that is not motivating.

According to the gender and age group in which the participants belonged to and according also to the length of working experience of the participants and the level of their education, it was found that women, people aged 33-46 years, people with the length of working experience between 1-9 years and people with a university degree were more frequently exposed to all of the observed harmful psychosocial factors of the working environment while the performing uninteresting work and work that is not motivating was only factor that has been more frequently reported by the employees with secondary and higher education.

Among participants who were exposed to harmful psychosocial factors of the working environment, there were $62.6 \%(107 / 171)$ of them who had one or more SBS symptoms compared to $42.9 \%$ (3/7) of those who were not exposed to such factors, but this difference was not statistically significant (Fisher's exact test; $\mathrm{p}=0.430)$. As the number of harmful psychosocial factors of the working environment to which participants were exposed grew, the number of participants who experienced one or more symptoms of SBS increased as well but these differences were not statistically significant (Fisher's exact test; $\mathrm{p}=0.428$ ) (Table 1).

The prevalence of symptoms of SBS as a result of the exposure to each of the observed harmful psychosocial factors of the working environment is shown separately in Table 2 . It is evident that the smallest number of participants who have the SBS symptoms was established among participants who performed uninteresting work and work that is not motivating $(58.8 \%)$, while the largest number of participants with the SBS symptoms was established among those who did not have an ability to influence the quality of their own work conditions (71.1\%), where in the latter case the determined difference was statistically significant $\left(c^{2}=6.689 ; \mathrm{df}=1\right.$; $\mathrm{p}=0.013$ ) (Table 2).

When looking at all the participants in whom the existence of symptoms of SBS were determined, it was evident that among them $2.7 \%(3 / 110)$ were those who were not exposed to harmful psychosocial factors of the working environment, $38.2 \%$ (42/110) were exposed to one, $46.4 \%$ (51/110) were exposed to two, $10.0 \%(11 / 110)$ were exposed to three, and $2.7 \%$ (3/110) were exposed to four harmful psychosocial factors of the working environment. 
TABLE 1. Participants according to the gender and existence of symptoms of SBS and according to the exposure to a various number of harmful psychosocial factors of the working environment

\begin{tabular}{|c|c|c|c|c|c|c|}
\hline \multirow[t]{2}{*}{ Gender } & \multirow{2}{*}{$\begin{array}{l}\text { Existence of } \\
\text { symptoms } \\
\text { of SBS }\end{array}$} & \multicolumn{5}{|c|}{$\begin{array}{c}\text { Number of harmful psychosocial factors of the working environment to which } \\
\text { participants were exposed }\end{array}$} \\
\hline & & 0 & 1 & 2 & 3 & 4 \\
\hline \multirow[t]{2}{*}{ Male participants } & No/N (\%) & $2(50.0)$ & $15(57.7)$ & $11(44.0)$ & 0 & $1(50.0)$ \\
\hline & Yes/N (\%) & $2(50.0)$ & $11(42.3)$ & $14(56.0)$ & $3(100.0)$ & $1(50.0)$ \\
\hline Total & & 4 & 26 & 25 & 3 & 2 \\
\hline \multirow[t]{2}{*}{ Female participants } & No/N (\%) & $2(66.7)$ & $18(36.7)$ & $15(28.8)$ & $4(33.3)$ & 0 \\
\hline & Yes/N (\%) & $1(33.3)$ & $31(63.3)$ & 37 (71.2) & $8(66.7)$ & $2(100.0)$ \\
\hline Total & & 3 & 49 & 52 & 12 & 2 \\
\hline \multirow[t]{2}{*}{ All participants } & No/N (\%) & $4(57.1)$ & $33(44.0)$ & $26(33.8)$ & $4(26.7)$ & $1(25.0)$ \\
\hline & Yes/N (\%) & $3(42.9)$ & $42(56.0)$ & $51(66.2)$ & $11(73.3)$ & $3(75.0)$ \\
\hline Total & & 7 & 75 & 77 & 15 & 4 \\
\hline
\end{tabular}

TABLE 2. Participants exposed to a particular harmful psychosocial factor of the working environment according to the existence of symptoms of sick building syndrome

\begin{tabular}{lccc}
\hline Harmful psychosocial factor of the working environment & \multicolumn{2}{c}{ Existence of symptoms of SBS (N (\%)) } & \multirow{2}{*}{ p-value } \\
\cline { 2 - 3 } & No & Yes & \\
\hline Performing uninteresting work and work that is not motivating & $7(41.2)$ & $10(58.8)$ & 0.798 \\
Excess workload in the workplace & $60(37.7)$ & $99(62.3)$ & 0.804 \\
Inability to influence the quality of one's own work conditions & $26(28.9)$ & $64(71.1)$ & $0.013^{*}$ \\
Lack of social support from co-workers while performing the work & $8(36.4)$ & $14(63.6)$ & 1.000 \\
\hline
\end{tabular}

* $\chi^{2}$-test; " statistical significant difference

Comparing the participants with 1-3 and 4 or more symptoms of SBS according to the number of harmful psychosocial factors of the working environment to which these two groups of participants were exposed, it is evident that there were differences in the number of harmful psychosocial factors of the working environment among them, and these differences were statistically significant (Fisher's exact test; $\mathrm{p}=0.001)$ (Table 3).

\section{DISCUSSION}

The conducted study has shown that almost all of the employees $(96.1 \%)$ of public institutions from the city of Osijek (Eastern Croatia) were exposed to one or more harmful psychosocial factors of the working environment in their workplace. According to the frequency of each harmful psychosocial factors of the working environment to which participants at their workplace were exposed, it was established that $93.0 \%$ of participants experienced excessive workload at their workplace, $52.6 \%$ had no ability to influence the
TABLE 3. Participants with a various number of symptoms of sick building syndrome according to the number of harmful psychosocial factors of the working environment to which they were exposed

\begin{tabular}{lccc}
\hline $\begin{array}{l}\text { Number of harmful } \\
\text { psychosocial factors } \\
\text { of the working }\end{array}$ & $\begin{array}{c}\text { Participants with a various } \\
\text { number of SBS symptoms } \\
\text { environment to }\end{array}$ & $\begin{array}{c}\text { Total } \\
\mathrm{N}(\%)\end{array}$ \\
\cline { 2 - 3 } $\begin{array}{l}\text { which participants } \\
\text { were exposed }\end{array}$ & $\begin{array}{c}\text { (N) }(\%)) \\
\text { symptoms }\end{array}$ & $\begin{array}{c}\text { 4 or more } \\
\text { symptoms }\end{array}$ \\
\hline 0 & $3(4.4)$ & 0 & $3(2.7)$ \\
1 & $34(50.0)$ & $8(19.0)$ & $42(38.2)$ \\
2 & $27(39.7)$ & $24(57.2)$ & $51(46.4)$ \\
3 & $3(4.4)$ & $8(19.0)$ & $11(10.0)$ \\
4 & $1(1.5)$ & $2(4.8)$ & $3(2.7)$ \\
Total & 68 & 42 & 110 \\
\hline
\end{tabular}

quality of their own work conditions, $12.9 \%$ did not have social support from their co-workers while performing the work, and $9.9 \%$ of them performed an uninteresting work and work that is not motivating. These results are comparable with the results of a study conducted in southern Finland, 
in which it was established that local employees are also often exposed to harmful psychosocial factors of the working environment, but all of these harmful psychosocial factors of the working environment were lower represented. Accordingly, 20.0\% of Finnish employees experienced excessive workload at their workplace, $21.0 \%$ of them had no ability to influence the quality of their own work conditions, $6.0 \%$ of them had no social support from their co-workers while performing the work and only $4.0 \%$ of them performed an uninteresting work and work that is not motivating (26).

When observing the correlation between exposure to harmful psychosocial factors of the working environment and gender of participants, this study showed that women are more often exposed to these harmful factors, which is in compliance with the results of studies conducted in Finland and Denmark $(26,27)$. The study further affirmed that persons aged 33-46 years were more frequently exposed to harmful psychosocial factors of the working environment, contrary to the study conducted in Finland according to which elderly employees, aged 45-54 years were more often exposed to these factors (26). The explanation for this result might be hidden in the fact that people in the age group of 33-46 years are in fact people who are in the most productive period of their life, predominantly focused at career advancement. Because of that, this group of employees sometimes consciously work a lot, often performing uninteresting work and work that is not motivating without thinking about the possibilities of influencing the quality of one's own work conditions and not expecting too much social support from co-workers who often perceived them as a competition because they are also climbing the career ladder. In terms of the length of the working experience of the participants and their level of education present study showed that people with the length of working experience between 1-9 years and people with a university degree were more frequently exposed to all of the observed harmful psychosocial factors of the working environment. This result is difficult to compare with the results of other similar studies carried out in the world because they have not dealt with the connections between mentioned variables. The possible explanation lies in the fact that employees with the aforementioned length of working experience and university degree, similar to the above mentioned employees aged between 33-46 years, are in fact people who are in that stage of their life where they are primarily focused at career advancement and because of that sometimes consciously exposed themselves to various harmful psychosocial factors of the working environment.

The fact that in our study, employees with secondary and higher level of education have more often reported the performance of an uninteresting work and work that is not motivating can be easily explained by their subordinate position in the work hierarchy, following which they are forced to do all the work assignments that their superiors instruct them to do, while some of these work assignments are sometimes uninteresting and not motivating.

This study further showed that participants who were exposed to harmful psychosocial factors of the working environment are more likely to experience SBS symptoms compared to those who were not exposed to such harmful factors in the workplace, which is in compliance with the results of the similar studies conducted in Sweden, the UK, Finland and Denmark (10,18,26-29). Furthermore, the study showed that the increase of the number of harmful psychosocial factors of the working environment that participants were exposed to is accompanied by the increase in the number of participants who experienced one or more symptoms of SBS, which is in compliance with the results of similar studies conducted elsewhere in the world (26).

Present study established that among the observed harmful psychosocial factors of the working environment, it is the very inability of participants to influence the quality of their own work conditions that contributes the most to the development of SBS symptoms, which is consistent with the results of the studies conducted elsewhere in the world (18). Finally, this study determined that exposure to a greater number of harmful psychosocial factors of the working environment is associated with a development of a larger number of SBS symptoms that was also shown in other similar studies (26).

Our study has several limitations that should be considered when evaluating the obtained results. One of the limitations refers to the geographical limitations of study in the area of the Eastern 
Croatia which somewhat limits the generalization of study results to all the employees in Croatia due to possible differences in the psychosocial factors of the working environment to which employees from the different parts of Croatia are exposed. In addition, since the participation in the study was voluntary, the possibility that some employees, although exposed to some or all of the studied harmful psychosocial factors of the working environment which caused them to experience SBS symptoms, avoided involvement in the study simply because of fear of adverse consequences in the workplace. Besides that the limitation of the study is the lack of analysis of physical environmental conditions of office buildings and also uneven gender representation of study participants. The latter one is a due to still present traditional labor division in Croatian society where females more often work in offices in comparison to males. Finally, since the study is designed as a cross-sectional study, definitive conclusions about the established cause-effect relationships between the patterns of appearance of symptoms of SBS and the observed harmful psychosocial factors of the working environment cannot be drown.

\section{CONCLUSION}

This study determined a very frequent exposure of the employees of public institutions of Eastern Croatian to harmful psychosocial factors of the working environment, as highly significant risk factors for the development of SBS among employees. The study confirmed that among the employees who were exposed to harmful psychosocial factors of the working environment symptoms of SBS were more common compared to those employees who were not exposed to such influences in the workplace, where the incidence and the number of SBS symptoms was growing in parallel with the increase in the number of harmful psychosocial factors of the working environment to which the employees were exposed. The most important identified harmful factors of the working environment in this study were an excessive workload at the workplace and the inability of employees to influence the quality of their own work conditions and it was demonstrated that the exposure to the latter factor contributes the most to the development of SBS symptoms.
Considering the prevalence of Eastern Croatia employees' exposure to harmful psychosocial factors of the working environment and considering also the proven relationship between these factors and the incidence of SBS symptoms that can significantly impair the health and productivity of employees, this issue arises as an extremely important issue in the field of occupational medicine and health protection at workplace.

Accordingly, it seems that, the continuous implementation of preventive activities in the workplace aimed at preventing and mitigating the impact of harmful psychosocial factors of the working environment, is the most important and most profitable measure for preventing the development of SBS symptoms, that will also, in long term, significantly improve the health, as well as, labor productivity of the employees.

\section{CONFLICT OF INTEREST}

The authors declare no conflict of interest.

\section{REFERENCES}

1. World Health Organization. Indoor Air Pollutants: exposure and health effects. Report on a WHO meeting. EURO reports and studies, no.78. Copenhagen: WHO Regional Office for Europe, 1983.

2. Beneš M. Sick building syndrome in public institutions in city of Osijek. Graduate thesis [in Croatian]. Osijek: Faculty of Medicine, 2013.

3. Gomzi M, Bobić J. Sick Building Syndrome: Do We Live and Work in Unhealthy Environment? Period. Biol. 2009;111(1):79-84.

4. Burge PS. The sick building syndrome. Occup. Environ. Med. 2004;61(2):185-90 http://dx.doi.org/10.1136/oem.2003.008813.

5. Kreiss K. Sick Building Syndrome and Building-related IIIness. In: Rom WN, Markowitz SB, editors. Environmental and Occupational Medicine, $4^{\text {th }}$ edition. Philadelphia: Lippincott Williams \& Wilkins; 2007, p.1373-80.

6. Petrović G, Miškulin M. Housing and health. In: Puntarić D, Miškulin M, Bošnir J, editors. Health ecology [in Croatian]. Zagreb: Medicinska naklada; 2012, p. 351-76.

7. Sahlberg B, Gunnbjörnsdottir M, Soon A, Jogi R, Gislason T, Wieslander G et al. Airborne molds and bacteria, microbial volatile organic compounds (MVOC), plasticizers and formaldehyde in dwellings in three North European cities in relation to sick building syndrome (SBS). Sci. Total. Environ. 2013;444:433-40 http://dx.doi.org/10.1016/j.scitotenv.2012.10.114.

8. Wang J, Li B, Yang Q, Yu W, Wang H, Norback D, et al. Odors and sensations of humidity and dryness in relation to sick building syndrome and home environment in Chongqing, China. PloS. One. 2013;8(8):e72385 http://dx.doi.org/10.1371/journal.pone.0072385.

9. Brasche S, Bullinger M, Morfeld M, Gebhardt HJ, Bischof W. Why do women suffer from sick building syndrome more often than men? Subjective higher sensitivity versus objective causes. Indoor. Air. 2001;11(4):217-22 http:// dx.doi.org/10.1034/j.1600-0668.2001.110402.x.

10. Runeson R, Wahlstedt K, Wieslander G. Personal and psychosocial factors and symptoms compatible with sick building syndrome in the Swedish workforce. Indoor. Air. 2006;16(6):445-53 http://dx.doi. org/10.1111/j.1600-0668.2006.00438.x. 
11. Chao HJ, Schwartz J, Milton DK, Burge HA. The work environment and workers' health in four large office buildings. Environ. Health. Perspect. 2003;111(9):1242-8 http://dx.doi.org/10.1289/ehp.5697.

12. Bornehag CG, Blomquist $G$, Gyntelberg $F$, Järvholm B, Malmberg $P$, Nordvall $L$, et al. Dampness in buildings and health. Nordic interdisciplinary review of the scientific evidence on associations between exposure to "dampness" in buildings and health effects (NORDDAMP). Indoor. Air. 2001;11(2):72-86 http://dx.doi.org/10.1034/j.1600-0668.2001.110202.x.

13. Engvall K, Norrby $C$, Norbäck D. Ocular, airway, and dermal symptoms related to building dampness and odors in dwellings. Arch. Environ. Health. 2002;57(4):304-10 http://dx.doi.org/10.1080/00039890209601413.

14. Engvall K, Wickman P, Norbäck D. Sick building syndrome and perceived indoor environment in relation to energy saving by reduced ventilation flow during heating season: a 1 year intervention study in dwellings. Indoor. Air. 2005;15(2):120-6 http://dx.doi.org/10.1111/j.1600-0668.2004.00325.x.

15. Redlich CA, Sparer J, Cullen MR. Sick-building syndrome. Lancet. 1997;349(9057):1013-6 http://dx.doi.org/10.1016/S0140-6736(96)07220-0

16. Daisey JM, Angell WJ, Apte MG. Indoor air quality, ventilation and health symptoms in schools: an analysis of existing information. Indoor. Air. 2003;13(1):53-64 http://dx.doi.org/10.1034/j.1600-0668.2003.00153.x.

17. Bobić J, Gomzi M, Radošević-Vidaček B, Kanceljak-Macan B. Association of neuroticism with sick building syndrome, quality of life and psychomotor performance. Coll. Antropol. 2009;33(2):567-72.

18. Marmot AF, Eley J, Stafford M, Stansfeld SA, Warwick E, Marmot MG. Building health: an epidemiological study of "sick building syndrome" in the Whitehall II study. Occup. Environ. Med. 2006;63(4):283-9 http://dx.doi. org/10.1136/oem.2005.022889.

19. Guo P, Yokoyama K, Piao F, Sakai K, Khalequzzaman M, Kamijima M, et al. Sick building syndrome by indoor air pollution in Dalian, China. Int. J. Environ. Res. Public. Health. 2013;10(4):1489-504 http://dx.doi. org/10.3390/ijerph10041489.

20. Rios JL, Boechat JL, Gioda A, dos Santos CY, de Aquino Neto FR, Lapa e Silva JR. Symptoms prevalence among office workers of a sealed versus a non-sealed building: associations to indoor air quality. Environ. Int 2009;35(8):1136-41 http://dx.doi.org/10.1016/j.envint.2009.07.005.

21. Mendell MJ, Lei-Gomez Q, Mirer AG, Seppänen O, Brunner G. Risk factors in heating, ventilating, and air-conditioning systems for occupant symptoms in US office buildings: the US EPA BASE study. Indoor. Air. 2008;18(4):301-16 http://dx.doi.org/10.1111/j.1600-0668.2008.00531.x.

22. Abdel-Hamid MA, A Hakim S, Elokda EE, Mostafa NS. Prevalence and risk factors of sick building syndrome among office workers. J. Egypt. Public. Health. Assoc. 2013;88(2):109-14 http://dx.doi.org/10.1097/01. EPX.0000431629.28378.c0.

23. Reijula K, Sundman-Digert C. Assessment of indoor air problems at work with a questionnaire. Occup. Environ. Med. 2004;61(1):33-8.

24. Sega K, Kalinić N. Sick building syndrome-a case study in Zagreb. Arh. Hig. Rada. Toksikol. 1994;45(1):1-10.

25. Gomzi M, Bobić J, Radošević-Vidaček B, Macan J, Varnai VM, MilkovićKraus S, et al. Sick building syndrome: psychological, somatic and environmental determinants. Arch. Environ. Occup. Health. 2007;62(3):147-55 http://dx.doi.org/10.3200/AEOH.62.3.147-155.

26. Lahtinen M, Sundman-Digert C, Reijula K. Psychosocial work environment and indoor air problems: a questionnaire as a means of problem diagnosis. Occup. Environ. Med. 2004;61(2):143-9 http://dx.doi.org/10.1136/ oem.2002.005835.

27. Hansen AM, Meyer HW, Gyntelberg F. Building-related symptoms and stress indicators. Indoor. Air. 2008;18(6):440-6 http://dx.doi. org/10.1111/j.1600-0668.2008.00571.x.

28. Skov P, Valbjørn O, Pedersen BV. Influence of personal characteristics, job-related factors and psychosocial factors on the sick building syndrome. Danish Indoor Climate Study Group. Scand. J. Work. Environ. Health. 1989;15(4):286-95 http://dx.doi.org/10.5271/sjweh.1851.

29. Runeson-Broberg R, Norbäck D. Sick building syndrome (SBS) and sick house syndrome (SHS) in relation to psychosocial stress at work in the Swedish workforce. Int. Arch. Occup. Environ. Health. 2013;86(8):91522 http://dx.doi.org/10.1007/s00420-012-0827-8. 